\title{
Appropriate intensification of diabetes- related therapy by general practitioners: cross sectional study
}

\section{Original Research Paper}

\author{
Dr. Nelson Aguirre M.D Ph.D (correspondence) \\ Honorary Academic \\ Health systems Department, School of Population Health, \\ University of Auckland, Auckland 1072, \\ New Zealand \\ n.aguirre@auckland.ac.nz
}

Dr. Peter Carswell Ph.D.

Senior Lecturer. Health systems Department, School of Population Health, University of Auckland, Auckland 1072,

New Zealand

p.carwell@auckland.ac.nz

\section{Correspondence}

Nelson Aguirre-Duarte, Health Systems Department, School of Population health, The University of Auckland, Private Bag 92019, Auckland 1142 New Zealand. Email: n.aguirre@auckland.ac.nz 


\section{ABSTRACT}

Aim: To measure intensification of therapy (the inverse of clinical inertia) by general practitioners in the management of hyperglycaemia, hypertension and dyslipidaemia in patients with diabetes.

Methods: We analysed clinical practices results for $\mathrm{Hb} 1 \mathrm{C}$, blood pressure, lipids and pharmacy records for prescriptions according to the guidelines. We identified whether medication was increased at each patient visit when the goals for glycosylated haemoglobin ( $<=64 \mathrm{mmol} / \mathrm{mol}$ ), systolic blood pressure $(<=130 \mathrm{mmHg})$ and $\mathrm{LDL}$ cholesterol $(<=3.5 \mathrm{mmol} / \mathrm{L})$ had not been reached at the time of the visit. The study was conducted between January 2009 and December 2011 in South Auckland, New Zealand.

Results: Data from 314 patients with diabetes included 2398 prescriptions. Appropriate intensification of therapy was seen in $31 \%$ of 457 visits when HbA1c was raised, $11 \%$ of 375 visits when systolic blood pressure was raised and $2 \%$ of 51 visits when LDL cholesterol was raised.

Conclusions: There are clear differences in intensification therapy in terms of the co-morbidity addressed. Clinical inertia may be one important and changeable contributor to diabetes complications. New Zealand has replaced "get Checked" programme for Diabetes Care Improvement Package, which is a primary care based programme seeking to improve outcomes for people with diabetes. This new programme is based on coordination of diabetes care, therefore a further analysis measuring clinical inertia may show improvements in quality, consistency and direction of care for people with diabetes in New Zealand. 


\section{Highlights:}

- We measure intensification of therapy by general practitioners.

- Management of hyperglycaemia, hypertension and dyslipidaemia were tested.

- There are differences in intensification therapy in terms of each co-morbidity.

- Clinical inertia may be one changeable contributor to diabetes complications. 


\section{INTRODUCTION}

Chronic diseases such as diabetes can have devastating consequences on morbidity, mortality and cost $(1,2)$. The prevalence of diabetes and related diseases is increasing worldwide(3-5). There is a vast amount of clinical evidence suggesting the benefits of the glycaemic control $(6,7)$, however more than $40 \%$ of these patients struggle to reach those targets $(8,9)$.

Management of type 2 diabetes in New Zealand is largely undertaken in primary care, with diabetes specialists involved in care of more complex patients and in support of primary care providers.(10) General practitioners (GPs) act as a central contact point for patients with type 2 diabetes and share, with patients, the primary responsibility for achieving optimal outcomes.(11-13) Nevertheless GPs will sometimes fail to increase therapy when it appears to be indicated, action that is recognised as clinical inertia.(14-17)

Observational studies in the U.S, Canada and Europe have shown rates of clinical inertia between $25 \%$ and $83 \%$. $(16,18)$ Several different methods have been proposed to measure clinical inertia. $(16,17,19)$ In the case of diabetes, measurement should go beyond pharmaceutical management of glucose control to include therapy for blood pressure and cholesterol.(20) Clinical inertia may one of the reasons why patients with diabetes do not reach management goals. Measuring intensification of therapy as a the first steps to understand the size of the problem and perhaps point to ways to support GPs managing patients with diabetes.(17) 
The primary goal of this study was to measure the percentage of clinical inertia over the time in response to the clinical needs of the patients, in a region with high prevalence of diabetes in New Zealand.

\section{METHODS}

\section{Context}

Counties Manukau in South Auckland, New Zealand, had about 470,000 residents in 2011 , of whom $8 \%$ of the adult population, accounting for $14 \%$ of people with diabetes in New Zealand. $(21,22)$ Health care is funded by a tax-based system in which secondary care is free to the patient, and primary care and pharmaceuticals are heavily subsidised. "Get checked" programme was a diabetes follow up care fully funded in New Zealand which ceased on July 2012 after one decade. The programme gave diabetes patients access to a free annual health check, including key tests and prescriptions based on planning for the year ahead.(21).

\section{Data Sources}

Data were provided by a Primary Health Organisation (PHO). Measures of blood pressure, $\mathrm{HbA}_{1 \mathrm{c}}$ and LDL cholesterol (clinical data) came from data submitted by general practices to the PHO for payment under the annual review programme. Prescription data was collected directly by the PHO from community pharmacies; all the prescriptions were already dispensed by patients. The PHO was not able to collect data in all the practices, as they used different software and formats. In other cases, general practice managers did not allow downloading of their prescription databases.

Study Subjects 
medRxiv preprint doi: https://doi.org/10.1101/2020.04.07.20057380; this version posted April 10, 2020. The copyright holder for this preprint

We invited all practices affiliated with the PHO, located in Counties Manukau, who had submitted diabetes annual reviews for patients with type 2 diabetes. This included more than 140 GPs in 80 general practices. Patient inclusion criteria were: type 2 diabetes; at least two primary care visits during the 6 months period beginning Jan 2009; a measurement for at least one of $\mathrm{HbA}_{1 c}$, systolic blood pressure or $\mathrm{LDL}$ cholesterol in the 18 months prior to their first included visit; and at least one primary care visit between 1 and $1 \frac{1 / 2}{2}$ years after the index visit.

\section{Analysis}

We considered each medication dispensing as evidence of a medical decision that this medication was appropriate for this patient at this time. We assessed each dispensed medication against data assumed to be available to the prescribing doctor - blood pressure measured on the day of dispensing or earlier, and HbA1c \& cholesterol tested / result date (which) one day or more prior to dispensing, or earlier. In cases where no clinical data were available since the previous prescription, no judgement about appropriateness could be made.

Schmittdiel et al. defined intensification of treatment as meeting one or more of three criteria: an increase in the number of drug classes; an increase in the daily dosage of at least one ongoing drug class; or a switch to a medication in a different drug class. We grouped medications into classes: seven classes for blood pressure (ACE inhibitors, angiotensin antagonists, beta adrenergic blockers, calcium channel blockers, thiazides/related diuretics, potassium-sparing diuretics, and loop diuretics); five class for hyperlipidaemia (statins, bile acid resins, fibrates, niacin, and ezetimibe), and four class for glucose control (sulfonylureas, metformin, thiazolidinedione, and insulin); combination 
pills were considered as consisting of two classes.(23) Novel agents such as GLP-1s, and DDP VI were not included in the study as they are not part of the diabetes management in primary care in new Zealand.

Target values for HbA1c (<64), systolic BP $(<130)$ and LDL $(<3.4)$ were determined from target values used in previous studies of clinical inertia(16, 17, 20, 24, 25) and from New Zealand cardiovascular and diabetes management guidelines at the time.(26) Participating GPS considered these targets as appropriate (semi-structured interviews not reported here). A value above target that did not result in a change of medication at the next prescription was taken as evidence of clinical inertia, or failure to intensify therapy.

Intensification of treatment was calculated for each clinical category (glucose, blood pressure and cholesterol) as the number of prescriptions that showed intensification divided by the number of prescriptions.

Data management and analysis of the data were performed using Stata 11.1 for Windows (Stata, College Station, Texas).

\section{Ethics}

All participating GPs provided written informed consent. Patients with diabetes were not identifiable all data were anonymised by the PHO. Ethics approval was obtained from Northern X Regional Ethics Committee reference NTX/11/EXP/150.

\section{RESULTS}

The study sample consisted of 314 patients with diabetes, managed by 14 GPs over 2,398 prescriptions. All patients had diabetes, and most also had antihypertensive therapy (76\%) and antilipemic therapy 
(62\%). Table 1 summarises patients' clinical data and numbers and clinical management.

Table 1. Characteristics of 314 patients with type 2 diabetes

\begin{tabular}{|c|c|}
\hline Characteristics & Number / (\%) \\
\hline Clinical Data & $68.2 \pm 21.5$ \\
\hline $\begin{array}{c}\text { HbA1c mean (mmol/mol) } \\
\text { (mmHg) }\end{array}$ & $134 \pm 17.9$ \\
\hline LDL mean (mmol/L) & $2.27 \pm 0.77$ \\
\hline Prescriptions by type of drug & 2,398 \\
\hline Antidiabetic (oral and insulin) & $812(34 \%)$ \\
\hline Antihypertensive & $553(23 \%)$ \\
\hline Antilipidemic & \\
\hline
\end{tabular}

Management of goals

All patients with diabetes were prescribed with oral drugs and/or insulin during the study period. A total of 78 from 314 (25\%) patients and 268 from 2,398 (11\%) prescriptions involve insulin. A change in medication therapy was considered necessary at $37 \%$ of all visits overall, shown by therapeutic category in Table 2.

Table 2. Intensification of therapy 
Visits where HbA1c above $64 \mathrm{mmol} / \mathrm{mol}$

Prescriptions showed Intensification of therapy

Visits where systolic blood pressure above $130 \mathrm{mmHg}$.

Prescriptions showed intensification of therapy

Visits where LDL cholesterol above 3.5 $\mathrm{mmol} / \mathrm{L}$

Prescriptions showed intensification of therapy
$467(45 \%)$

$144(32 \%)$

$375(46 \%)$

$42(11 \%)$

$51(9 \%)$

$1(2 \%)$

An average intensification percentage, per condition, was calculated for each GP. Table 3 shows how is the distribution of the intensification therapy per general practitioner in each level of measure.

Table 3. Intensification Therapy by GP $(n=14)$

\begin{tabular}{|l|c|c|c|}
\hline \multirow{2}{*}{ GP code } & \multicolumn{2}{|c|}{$\%$ Intensification of Therapy } \\
\cline { 2 - 4 } & Glucose & $\begin{array}{c}\text { Blood } \\
\text { pressure } \\
\% \text { (denominator) } \\
\%(\text { denominator) }\end{array}$ & Cholesterol \\
& $33 \%(12)$ & $11 \%(9)$ & $100 \%(1)$ \\
\hline GD00114 & $50 \%(4)$ & $0 \%(3)$ & $0 \%(3)$ \\
\hline GD00120 & $54 \%(26)$ & $9 \%(46)$ & $0 \%(2)$ \\
\hline GD00310 & $31 \%(13)$ & $10 \%(10)$ & $0 \%(3)$ \\
\hline GD00312 & $42 \%(26)$ & $0 \%(9)$ & $0 \%(3)$ \\
\hline GD00330 & & & \\
\hline
\end{tabular}




\begin{tabular}{|l|c|c|c|}
\hline GD00335 & $38 \%(56)$ & $7 \%(57)$ & $\cdot$ \\
\hline GD00427 & $12 \%(90)$ & $10 \%(10)$ & $0 \%(11)$ \\
\hline GD00512 & $36 \%(137)$ & $20 \%(94)$ & $0 \%(16)$ \\
\hline GD00514 & $24 \%(33)$ & $13 \%(23)$ & $0 \%(2)$ \\
\hline GD00535 & $43 \%(21)$ & $4 \%(49)$ & $0 \%(4)$ \\
\hline GD00630 & $0 \%(5)$ & $0 \%(5)$ & $\cdot$ \\
\hline GD00731 & $11 \%(18)$ & $10 \%(20)$ & $\cdot$ \\
\hline GD00926 & $33 \%(15)$ & $8 \%(12)$ & $0 \%(1)$ \\
\hline GD00930 & $36 \%(11)$ & $14 \%(28)$ & $0 \%(5)$ \\
\hline
\end{tabular}

\section{DISCUSSION}

Rates of clinical inertia shown by GP prescriptions for patients with type 2 diabetes in Counties Manukau range were 69\% for glucose control, 92 for blood pressure and $91 \%$ for cholesterol. There was considerable variation between GPs. These rates of clinical inertia could substantially contribute to diabetes complication rates. We note that clinical inertia measured in this way, while consistent with the literature, does not allow for the fact that changes of therapy are negotiated with patients, and there will be times when practitioner and patient agree to assess the effect of lifestyle modification before increasing pharmaceutical management.

This study is consistent with findings in previous research in primary care. $(18,27,28)$ Van Bruggen et al reported clinical inertia in diabetic 
medRxiv preprint doi: https://doi.org/10.1101/2020.04.07.20057380; this version posted April 10, 2020. The copyright holder for this preprint

patients as $43 \%$ for glucose control, $63 \%$ for blood pressure and $90 \%$ for cholesterol. Also in diabetic patients, Rodondy et al reported rates $34 \%, 36 \%$ and $44 \%$ respectively. In each case the clinical inertia rates are in the same rank order as for our study. This is likely to reflect the ongoing disproportionate emphasis on glucose control that is typical internationally.

This study describes proportions of clinical inertia rather than exploring causality. Explanations in the literature included physician's overestimation of their adherence to guidelines, acceptance of elevated risk factors levels in their patients, and low motivation to treat asymptomatic chronic conditions.(29-31) Systematic attempts to improve rates of clinical inertia have been relatively intensive and may not be easily reproduced in routine practice. One example is how reminders and feedback from endocrinologist in secondary care to GPs about intensification of therapy could improve prescription behaviour. (32) However a more holistic approach taking in account health system barriers, the provider, and patient is needed in order to have a better understanding of this issue and implement better strategies to increase the intensification therapy. (33)

The Ministry of health made the decision to stop the "get Checked" programme based on the results after 10 years. One of the reasons was the marginal clinical improvements for people with diabetes in new Zealand. (34) The current study supports those findings, in the way that clinical inertia is a relevant issue that may explain the disappointing clinical outcomes on this population.

There are several limitations to our study. The GPs who agreed to contribute data may not be representative of other GPs. Given that study volunteers are generally considered to be among the better 
performers, this may lead to an underestimate of clinical inertia. We noted earlier that intensification of therapy includes agreement with the patient, not accounted for in our measurements, which may lead to us over-estimating clinical inertia. A small proportion of prescriptions for diabetic patients come from secondary care or after-hours clinics rather than from the patient's usual doctor. Where blood pressure and laboratory results were not available between prescriptions it was not possible to adjudicate on clinical inertia, and it is unclear which direction this might affect our estimates. We used dispensing data (what the patient collects at the pharmacy) rather than prescribing rates (what the GP prescribes). There are times when a patient is given a prescription but does not collect the medication, perhaps due to cost. In a similar population we have previously shown about a $7 \%$ difference between prescription and dispensing.(35)

Despite these shortcomings, we have shown rates of clinical inertia to be sufficiently high to impact on diabetes complication rates. It therefore warrants further study of causation and evaluations of efforts to address it. New Zealand has replaced "get Checked" programme for Diabetes Care Improvement Package, which is a primary care based programme seeking to improve outcomes for people with diabetes. This new programme is based on coordination of diabetes care, therefore a further analysis measuring clinical inertia may show improvements in quality, consistency and direction of care for people with diabetes in New Zealand.

\section{Conflicts of Interest}

None

\section{Funding}

None 
medRxiv preprint doi: https://doi.org/10.1101/2020.04.07.20057380; this version posted April 10, 2020. The copyright holder for this preprint (which was not certified by peer review) is the author/funder, who has granted medRxiv a license to display the preprint in perpetuity.

It is made available under a CC-BY-NC-ND 4.0 International license .

\section{Acknowledgements}

We would like to thank all General Practitioners who took part in the study. And Paul

Roseman and his team in ProCare PHO for support and assistance during the data collection.

\section{References}

1. Wild S, Roglic G, Green A, Sicree R, King H. Global prevalence of diabetes estimates for the year 2000 and projections for 2030. Diabetes care. 2004;27(5):1047-53.

2. Whiting DR, Guariguata L, Weil C, Shaw J. IDF diabetes atlas: global estimates of the prevalence of diabetes for 2011 and 2030. Diabetes research and clinical practice. 2011;94(3):31121.

3. Wolf-Maier K, Cooper R, Banegas J, Giampaoli S, Hense H-W, Joffres M, et al. Hypertension prevalence and blood pressure levels in 6 european countries, canada ad united states. JAMA. 2003;289(18).

4. WHO. 2008-2013 action plan for the global strategy for the prevention and control of noncommunicable diseases: prevent and control cardiovascular diseases, cancers, chronic respiratory diseases and diabetes. 2009.

5. Guariguata L, Whiting D, Hambleton I, Beagley J, Linnenkamp U, Shaw J. Global estimates of diabetes prevalence for 2013 and projections for 2035. Diabetes research and clinical practice. 2014;103(2):137-49.

6. Association AD. Standards of Medical Care in Diabetes-2017 Abridged for Primary Care Providers. Clinical Diabetes. 2016.

7. Organization WH. Global report on diabetes: World Health Organization; 2016.

8. Khunti K, Wolden ML, Thorsted BL, Andersen M, Davies MJ. Clinical inertia in people with type 2 diabetes: a retrospective cohort study of more than 80,000 people. Diabetes Care. 2013;36(11):3411-7.

9. Ali MK, Bullard KM, Saaddine JB, Cowie CC, Imperatore G, Gregg EW. Achievement of Goals in U.S. Diabetes Care, 1999-2010. New England Journal of Medicine. 2013;368(17):1613-24.

10. Jackson G, Orr Walker B, Smith J, Papa D, Field A. Hospital admissions for people with diagnosed diabetes: challenges for diabetes prevention and management programmes. N Z Med J. 2009;122(1288):13-21.

11. Weenink JW, van Lieshout J, Jung HP, Wensing M. Patient Care Teams in treatment of diabetes and chronic heart failure in primary care: an observational networks study. Implement Sci. 2011;6(66):66.

12. Bodenheimer T, Wagner EH, Grumbach K. Improving primary care for patients with chronic illness.(The Chronic Care Model, part 2)(Innovations in Primary Care). 2002. p. 1909.

13. Rea H, Kenealy T, Horwood F, Sheridan N, Parsons M, Wemekamp B, et al. Integrated systems to improve care for very high intensity users of hospital emergency department and for long-term conditions in the community. The New Zealand Medical Journal. 2010;123(1320):76-85.

14. Giugliano D, Esposito K. Clinical inertia as a clinical safeguard. JAMA: The Journal of the American Medical Association. 2011;305(15):1591-2. 
medRxiv preprint doi: https://doi.org/10.1101/2020.04.07.20057380; this version posted April 10, 2020. The copyright holder for this preprint (which was not certified by peer review) is the author/funder, who has granted medRxiv a license to display the preprint in perpetuity. It is made available under a CC-BY-NC-ND 4.0 International license .

15. Phillips LS, Branch WT, Cook CB, Doyle JP, El-Kebbi IM, Gallina DL, et al. Clinical inertia. Ann Intern Med. 2001;135(9):825-34.

16. Grant RW, Cagliero E, Dubey AK, Gildesgame C, Chueh HC, Barry MJ, et al. Clinical inertia in the management of Type 2 diabetes metabolic risk factors. Diabet Med. 2004;21(2):150-5.

17. Berlowitz DR, Ash AS, Glickman M, Friedman RH, Pogach LM, Nelson AL, et al. Developing a quality measure for clinical inertia in diabetes care. Health Serv Res. 2005;40(6 Pt 1):1836-53.

18. Khunti K, Wolden ML, Thorsted BL, Andersen M, Davies MJ. Clinical Inertia in People With Type 2 Diabetes A retrospective cohort study of more than 80,000 people. Diabetes care. 2013.

19. El-Kebbi IM, Ziemer DC, Musey VC, Gallina DL, Bernard AM, Phillips LS. Diabetes in urban African-Americans. IX. Provider adherence to management protocols. Diabetes Care. 1997;20(5):698-703.

20. O'Connor PJ. Commentary--improving diabetes care by combating clinical inertia. Health Serv Res. 2005;40(6 Pt 1):1854-61.

21. Brady K. Ministry of health and district health boards: Effectiveness of the "Get Checked" diabetes programme. Wellington: Auditor-General Oot; 2007.

22. Dickson G, Philippon DJ, Marinelli-Poole A, McGilvray A, Lynes D. New Zealand health leadership. Leadership in Health Services. 2011;24(4):255-67.

23. Schmittdiel JA, Uratsu CS, Karter AJ, Heisler M, Subramanian U, Mangione CM, et al. Why don't diabetes patients achieve recommended risk factor targets? Poor adherence versus lack of treatment intensification. J Gen Intern Med. 2008;23(5):588-94.

24. Zafar A, Davies M, Azhar A, Khunti K. Clinical inertia in management of T2DM. Prim Care Diabetes. 2010;4(4):203-7.

25. Shah BR, Hux JE, Laupacis A, Zinman B, Van Walraven C. Clinical inertia in response to inadequate glycemic control: do specialists differ from primary care physicians? diabetes Care. 2005;28(3):600.

26. New Zealand Guidelines G, New Zealand. Ministry of H. New Zealand cardiovascular guidelines handbook a summary resource for primary care practitioners. Wellington2009.

27. van Bruggen R, Gorter K, Stolk R, Klungel O, Rutten G. Clinical inertia in general practice: widespread and related to the outcome of diabetes care. Family practice. 2009;26(6):428-36.

28. Rodondi N, Peng T, Karter AJ, Bauer DC, Vittinghoff E, Tang S, et al. Therapy modifications in response to poorly controlled hypertension, dyslipidemia, and diabetes mellitus.(Author abstract). Annals of Internal Medicine. 2006;144(7):475.

29. Bolen SD, Bricker E, Samuels TA, Yeh HC, Marinopoulos SS, McGuire M, et al. Factors associated with intensification of oral diabetes medications in primary care provider-patient dyads: a cohort study. Diabetes Care. 2009;32(1):25-31.

30. Asai $\mathrm{Y}$, Heller R, Kajii E. Hypertension control and medication increase in primary care. Journal of Human Hypertension. 2002;16(5):313.

31. Oliveria SA, Lapuerta P, McCarthy BD, Italien GJ, Berlowitz DR, Asch SM. Physician- related barriers to the effective management of uncontrolled hypertension. (Original Investigation). Archives of Internal Medicine. 2002;162(4):413.

32. Ziemer DC, Doyle JP, Barnes CS, Branch WT, Jr., Cook CB, El-Kebbi IM, et al. An intervention to overcome clinical inertia and improve diabetes mellitus control in a primary care setting: Improving Primary Care of African Americans with Diabetes (IPCAAD) 8. Arch Intern Med. 2006;166(5):507-13.

33. Zafar A, Stone MA, Davies MJ, Khunti K. Acknowledging and allocating responsibility for clinical inertia in the management of Type 2 diabetes in primary care: a qualitative study. Diabet Med. 2015;32(3):407-13. 
medRxiv preprint doi: https://doi.org/10.1101/2020.04.07.20057380; this version posted April 10, 2020. The copyright holder for this preprint (which was not certified by peer review) is the author/funder, who has granted medRxiv a license to display the preprint in perpetuity. It is made available under a CC-BY-NC-ND 4.0 International license.

34. Kenealy T, Orr-Walker B, Cutfield R, Robinson E, Buetow S, Simmons D. Does a diabetes annual review make a difference? Diabetic Medicine. 2012;29(8):e217-e22.

35. Mabotuwana T, Warren J, Harrison J, Kenealy T. What Can Primary Care Prescribing Data Tell Us About Individual Adherence to Long-Term Medication? - Comparison to Pharmacy Dispensing Data. Pharmacoepidemiology and Drug Safety 2009;18(10):956-64. 